Alexander Koch*, Manuel Jäger, Anja Völzke, Georgios Grammatikos,

Dagmar Meyer zu Heringdorf, Andrea Huwiler and Josef Pfeilschifter

\title{
Downregulation of sphingosine 1-phosphate (S1P) receptor 1 by dexamethasone inhibits S1P- induced mesangial cell migration
}

\begin{abstract}
Sphingosine 1-phosphate (S1P) is generated by sphingosine kinase (SK)-1 and -2 and acts mainly as an extracellular ligand at five specific receptors, denoted $\mathrm{S}_{1} \mathrm{P}_{1-5}$. After activation, S1P receptors regulate important processes in the progression of renal diseases, such as mesangial cell migration and survival. Previously, we showed that dexamethasone enhances SK-1 activity and S1P formation, which protected mesangial cells from stress-induced apoptosis. Here we demonstrate that dexamethasone treatment lowered $\mathrm{S}_{1} \mathrm{P}_{1}$ mRNA and protein expression levels in rat mesangial cells. This effect was abolished in the presence of the glucocorticoid receptor antagonist RU-486. In addition, in vivo studies showed that dexamethasone downregulated $\mathrm{S}_{1} \mathrm{P}_{1}$ expression in glomeruli isolated from mice treated with dexamethasone (10 mg/kg body weight). Functionally, we identified $\mathrm{S}_{1} \mathrm{P}_{1}$ as a key player mediating S1P-induced mesangial cell migration. We show that dexamethasone treatment significantly lowered S1P-induced migration of mesangial cells, which was again reversed in the presence of RU-486. In summary, we suggest that dexamethasone inhibits S1Pinduced mesangial cell migration via downregulation of $\mathrm{S} 1 \mathrm{P}_{1}$. Overall, these results demonstrate that dexamethasone has functional important effects on sphingolipid metabolism and action in renal mesangial cells.
\end{abstract}

Keywords: glucocorticoids; kidney; mesangial cell; sphingolipids; sphingosine 1-phosphate; S1P receptor.

\footnotetext{
*Corresponding author: Alexander Koch, pharmazentrum frankfurt/ ZAFES, Goethe University Hospital, Theodor-Stern-Kai 7, D-60590 Frankfurt/Main, Germany, e-mail: koch@med.uni-frankfurt.de Manuel Jäger, Anja Völzke, Dagmar Meyer zu Heringdorf and Josef Pfeilschifter: pharmazentrum frankfurt/ZAFES, Goethe University Hospital, Theodor-Stern-Kai 7, D-60590 Frankfurt/Main, Germany Georgios Grammatikos: pharmazentrum frankfurt/ZAFES, Goethe University Hospital, Theodor-Stern-Kai 7, D-60590 Frankfurt/ Main, Germany; and Department of Medicine 1, Goethe University Hospital, Theodor-Stern-Kai 7, D-60590 Frankfurt/Main, Germany Andrea Huwiler: Institute of Pharmacology, University of Bern, Friedbühlstrasse 49, CH-3010 Bern, Switzerland
}

DOI 10.1515/hsz-2014-0288

Received December 1, 2014; accepted February 11, 2015; previously published online February 19, 2015

\section{Introduction}

Sphingosine 1-phosphate (S1P) is known to influence pathophysiologically important processes involved in the progression of numerous renal diseases (for review, see Koch et al., 2013a). S1P is generated via the activity of two different kinase subtypes, sphingosine kinase (SK)-1 and -2. Once generated, S1P can act either intracellularly via recently identified targets or most commonly via activation of five specific receptors on the cell surface, denoted as S1P $_{1-5}$ (for review, see Sanchez and Hla, 2004; Strub et al., 2010). After activation S1P receptors regulate mesangial cell migration and proliferation, cell survival and the formation of extracellular matrix components, which are all important steps in the pathogenesis of renal diseases (for review, see Koch et al., 2013a). The five known S1P receptors couple to and activate a variety of different $G$ proteins, namely $\mathrm{G}_{\mathrm{i}}\left(\mathrm{S} 1 \mathrm{P}_{1-5}\right), \mathrm{G}_{\mathrm{q}}\left(\mathrm{S}_{\mathrm{P}} \mathrm{P}_{2 / 3}\right)$, and $\mathrm{G}_{12 / 13}\left(\mathrm{~S}_{\mathrm{P}} \mathrm{P}_{2-5}\right)$ and are characterized by a cell-type-specific expression pattern (for review, see Sanchez and Hla, 2004). Thus, depending on the cell type and binding to a specific $G$ protein, activation of distinct S1P receptors may result in diverse functional outcomes. In this regard, it is generally known that activation of $\mathrm{S}_{1} \mathrm{P}_{1}$ and $\mathrm{S}_{1} \mathrm{P}_{3}$ triggers cell migration, whereas $\mathrm{S}_{2} \mathrm{P}_{2}$ is linked to anti-migratory effects (for review, see Sanchez and Hla, 2004). In renal mesangial cells, which mainly express $\mathrm{S}_{1-3}$ and $\mathrm{S}_{1} \mathrm{P}_{5}$ (Katsuma et al., 2002; Koch et al., 2013b), it was demonstrated previously that exogenous S1P stimulates cell migration (Klawitter et al., 2007). However, in contrast to the reported inhibitory effect of ${\mathrm{S} 1 \mathrm{P}_{2}}_{2}$ activation in various other cell types (for review, see Sanchez and Hla, 2004), we recently suggested a pro-migratory role of $\mathrm{S}_{2} \mathrm{P}_{2}$ for S1P-induced mesangial cell migration (Völzke et al., 2014). We demonstrated that exogenous S1P enhanced the activity of cyclooxygenase 2 (COX-2) and subsequently the formation of prostaglandin 
$\mathrm{E}_{2}\left(\mathrm{PGE}_{2}\right)$, which was abolished in the presence of the $\mathrm{S}_{2} \mathrm{P}_{2}$ antagonist JTE-013 and specific siRNA against this receptor subtype. Interestingly, pharmacological inhibition of COX-2 blocked the S1P-stimulated migratory response, suggesting that extracellular S1P triggers mesangial cell migration partially via the activation of the $\mathrm{S}_{1} \mathrm{P}_{2} / \mathrm{COX}-2$ signaling pathway (Völzke et al., 2014). Most notably, we also pointed out that the additional activation of $\mathrm{S}_{1} \mathrm{P}_{1}$ and $\mathrm{S}_{1} \mathrm{P}_{3}$ by S1P apparently contributes to the migratory response of mesangial cells without requiring COX-2 induction (Völzke et al., 2014). Taken together, these data demonstrate that extracellular S1P via activation of $\mathrm{S}_{1} \mathrm{P}_{1-3}$ triggers the migration of renal mesangial cells, which might be involved in the progression of renal diseases. In general, modulating sphingolipid pathways could be an attractive target for new treatment strategies and, moreover, might explain the known beneficial effects of classical renal protective drugs. In this context, we recently showed that glucocorticoids, e.g., dexamethasone, which are commonly used for the treatment of chronic inflammatory kidney diseases, have a protective effect on stress-induced apoptosis of glomerular mesangial cells (Förster et al., 2010). The authors demonstrated that this action involves activation of the sphingomyelin signaling module accompanied by a coordinated expression and stimulation of neutral ceramidase and SK-1 activities, which in turn result in increased cellular S1P levels and protection from staurosporine-induced apoptosis. These results may explain why glucocorticoids have been used successfully to treat numerous clinical conditions affecting the kidney, and provide strong evidence that the renoprotective actions can be partially explained by targeting SK-1 and S1P metabolism in resident glomerular cells.

However, so far nothing is known about the effect of glucocorticoids on S1P receptor expression and function in glomerular cells. In this study we investigated whether dexamethasone alters S1P receptor expression pattern in renal mesangial cells and in mouse glomeruli and whether this impacts on S1P-induced mesangial cell migration.

\section{Results}

\section{Dexamethasone downregulates $\mathbf{S 1 P}_{1}$ expression in renal mesangial cells}

First, we evaluated whether dexamethasone treatment alters the S1P receptor expression in renal mesangial cells. We treated rat mesangial cells for $24 \mathrm{~h}$ with increasing concentrations of dexamethasone (1-300 nM) and measured the mRNA expression levels using TaqMan ${ }^{\circledR}$ analysis. As shown in Table $1, \mathrm{~S}_{1} \mathrm{P}_{1}$ mRNA expression levels were significantly downregulated by this treatment. We also investigated whether dexamethasone treatment altered the expression of other S1P receptors in renal mesangial cells. The mRNA expression levels of $\mathrm{S}_{1} \mathrm{P}_{2}$ and $\mathrm{S}_{1} \mathrm{P}_{5}$ were not significantly altered after the treatment with increasing concentrations of dexamethasone (Table 1). The mRNA expression level of $\mathrm{S1P}_{4}$, which is normally not expressed in renal mesangial cells (Katsuma et al., 2002; Koch et al., 2013b), was also not affected upon stimulation with 1-300 nM dexamethasone for $24 \mathrm{~h}$ (data not shown). However, the $\mathrm{S} 1 \mathrm{P}_{3}$ mRNA expression was significantly downregulated after stimulation with 100 and $300 \mathrm{nM}$ dexamethasone (Table 1), whereas the protein expression of $\mathrm{S}_{3} \mathrm{P}_{3}$ upon stimulation with dexamethasone for $24 \mathrm{~h}$ was not altered (Figure 1E).

To further evaluate the effect of dexamethasone on $\mathrm{S}_{1} \mathrm{P}_{1}$ expression, we treated rat mesangial cells with $100 \mathrm{~nm}$ dexamethasone for different time periods (2-24 h). As shown in Figure 1A, stimulation with dexamethasone led to a strong downregulation of $\mathrm{S}_{1} \mathrm{P}_{1}$ mRNA expression at all of the time points investigated compared to the respective controls. Moreover, 4 and $24 \mathrm{~h}$ treatment of rat mesangial cells with $100 \mathrm{nM}$ dexamethasone significantly downregulated $\mathrm{S}_{1} \mathrm{P}_{1}$ mRNA (Figure 1B) as well as protein expression (Figure 1C). To verify whether dexamethasone alters $\mathrm{S}_{1} \mathrm{P}_{1}$ expression directly via activation of the glucocorticoid receptor (GR), we stimulated rat mesangial cells in parallel with $1 \mu \mathrm{M}$ of the GR antagonist RU-486 (Jung-Testas and Baulieu, 1983). Figures 1B and C clearly show that the reduction of $\mathrm{S}_{1} \mathrm{P}_{1} \mathrm{mRNA}$ and protein expression upon treatment with $100 \mathrm{~nm}$ dexamethasone was diminished in the presence of $1 \mu \mathrm{M}$ RU-486. Stimulation of rat mesangial cells with $1 \mu \mathrm{M}$ RU-486 alone for either

Table 1: Effect of dexamethasone on the mRNA expression levels of $\mathrm{S} 1 \mathrm{P}$ receptors in rat mesangial cells.

\begin{tabular}{lrrrrr}
\hline S1P & & & & & DEX (nM) \\
\cline { 2 - 6 } $\begin{array}{l}\text { receptor } \\
\text { subtype }\end{array}$ & 0 & 1 & 10 & 100 & 300 \\
\hline${\mathrm{S} 1 \mathrm{P}_{1}}$ & $100 \pm 0$ & $50.4 \pm 4.60^{\mathrm{a}}$ & $27.7 \pm 7.76^{\mathrm{a}}$ & $21.8 \pm 3.10^{\mathrm{a}}$ & $17.1 \pm 3.10^{\mathrm{a}}$ \\
$\mathrm{S}_{\mathrm{P}} \mathrm{P}_{2}$ & $100 \pm 0$ & $77.9 \pm 14.2$ & $70.4 \pm 7.02$ & $72.6 \pm 16.8$ & $83.7 \pm 15.6$ \\
$\mathrm{~S}_{\mathrm{P}}{ }_{3}$ & $100 \pm 0$ & $73.0 \pm 6.87$ & $71.4 \pm 16.9$ & $47.2 \pm 8.34^{\mathrm{b}}$ & $50.6 \pm 12.2^{\mathrm{b}}$ \\
${\mathrm{S} 1 \mathrm{P}_{5}}$ & $100 \pm 0$ & $102 \pm 25.2$ & $106 \pm 38.8$ & $131 \pm 15.3$ & $123 \pm 22.6$ \\
\hline
\end{tabular}

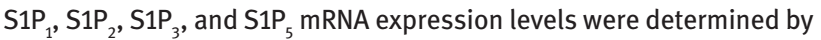
$\operatorname{TaqMan}^{\circledR}$ analysis after $24 \mathrm{~h}$ of treatment with the indicated concentrations of dexamethasone (DEX). Results are expressed as mean \pm SEM. $(\mathrm{n}=5) ;{ }^{\mathrm{a}} p<0.001,{ }^{\mathrm{b}} p<0.05$, compared to the respective controls. 
A

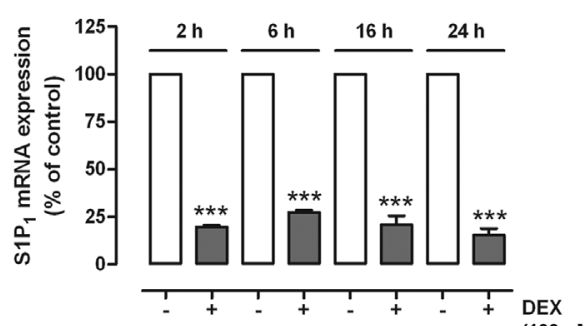

B
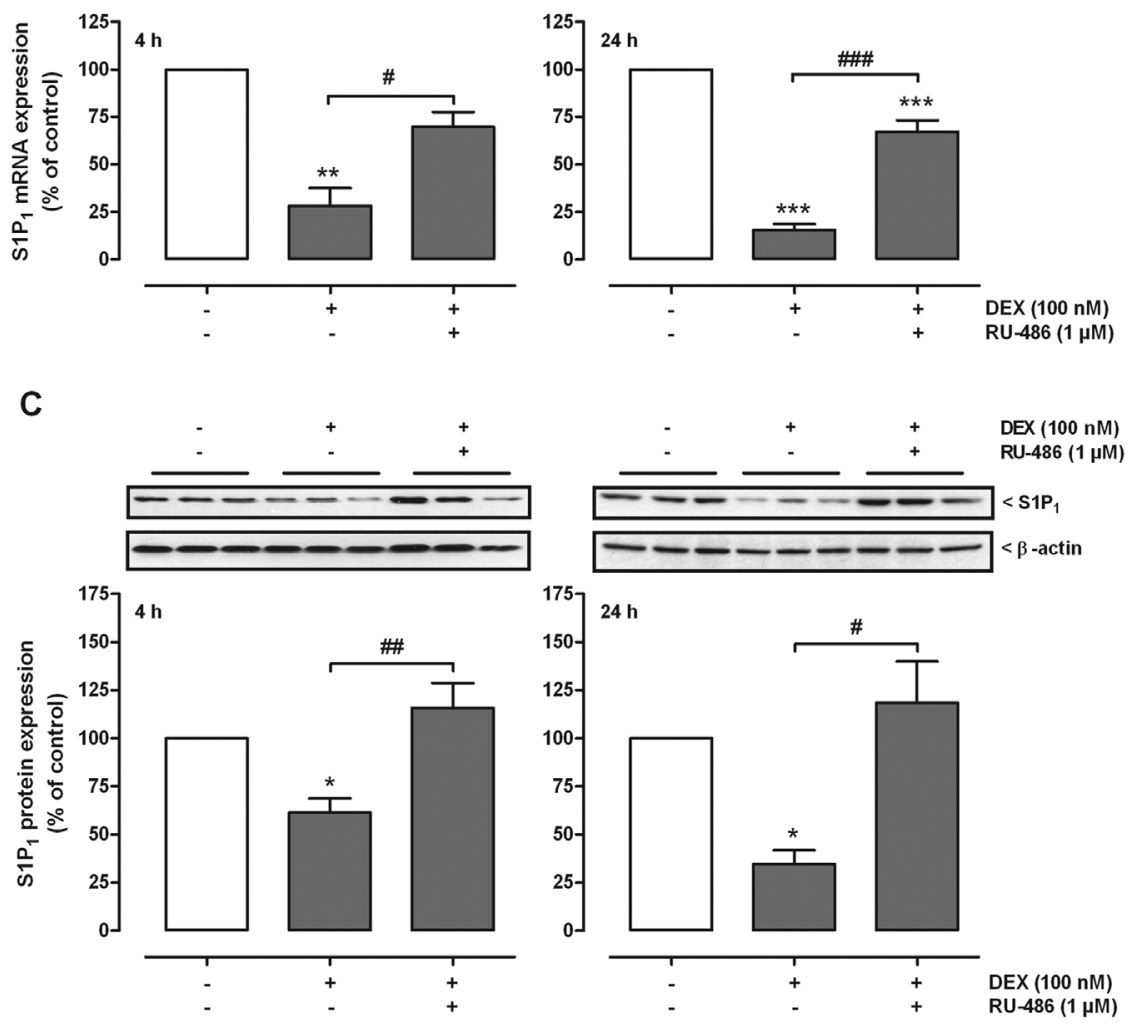

D

$\mathbf{E}$
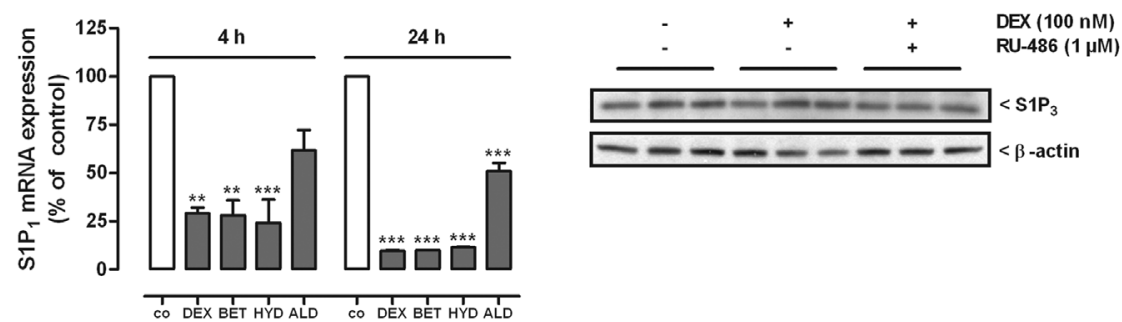

Figure 1: Dexamethasone downregulates $\mathrm{S}_{1} \mathrm{P}_{1}$ expression in rat mesangial cells.

(A) S1P ${ }_{1}$ mRNA expression levels after treatment with $100 \mathrm{~nm}$ dexamethasone (DEX) for the indicated time points. (B) S1P ${ }_{1}$ RNA expression levels after $4 \mathrm{~h}$ and $24 \mathrm{~h}$ of treatment with $100 \mathrm{~nm}$ DEX and $1 \mu \mathrm{m}$ RU-486. (A,B) S1P ${ }_{1}$ mRA expression levels (gray bars) were determined by TaqMan ${ }^{\circledR}$ analysis and are shown relative to control cells (vehicle alone, white bars). (C) S1P protein expression levels after $4 \mathrm{~h}$ and $24 \mathrm{~h}$ of treatment with $100 \mathrm{nM}$ DEX and $1 \mu \mathrm{M}$ RU-486 were determined by Western blot analysis. Bands corresponding to $\mathrm{S}_{1} \mathrm{P}_{1}$ and $\beta$-actin were densitometrically evaluated and are shown relative to control cells (vehicle alone; white bars; for representative Western blot, see upper panels). (D) S1P ${ }_{1}$ mRNA expression levels after $4 \mathrm{~h}$ and $24 \mathrm{~h}$ treatment with $100 \mathrm{~nm}$ dexamethasone (DEX), betamethasone (BET), hydrocortisone (HYD), and aldosterone (ALD). S1P ${ }_{1}$ mRNA expression levels (gray bars) were determined by TaqMan ${ }^{\circledR}$ analysis and are shown relative to control cells (vehicle alone, white bars). (E) Representative Western blot of $\mathrm{S}_{1} \mathrm{P}_{3}$ protein expression levels after $24 \mathrm{~h}$ treatment with $100 \mathrm{~nm}$ DEX and $1 \mu \mathrm{M}$ RU-486. All results are expressed as mean \pm SEM $(\mathrm{n}=3-5) .{ }^{\star} p<0.05,{ }^{\star \star} p<0.01,{ }^{\star \star \star} p<0.001$, compared to the respective controls. ${ }^{\#} p<0.05,{ }^{\# \#} p<0.01$, ${ }^{\# \#} p<0.001$, compared to dexamethasone-treated cells. 
4 or $24 \mathrm{~h}$ did not significantly influence the S1P $\mathrm{P}_{1}$ mRA expression [ $4 \mathrm{~h}$, control (vehicle alone) $=100 \pm 0$, RU-486 $(1 \mu \mathrm{M})=86.9 \pm 11.7 ; 24 \mathrm{~h}$, control (vehicle alone) $=100 \pm 0$, RU-486 $(1 \mu \mathrm{M})=79.2 \pm 9.77$; mean \pm SEM; $n=3$ ]. Furthermore, other glucocorticoids (betamethasone, hydrocortisone) and the mineralocorticoid aldosterone, which is also able to bind to the GR, downregulated $\mathrm{S}_{1} \mathrm{P}_{1}$ mRNA expression (Figure 1D), overall indicating that the downregulation of $\mathrm{S}_{1} \mathrm{P}_{1}$ is mediated by the GR.

Finally, we investigated whether the dexamethasonemediated reduction of $\mathrm{S}_{1} \mathrm{P}_{1}$ expression is also occurring in other species as well as in vivo. Therefore, we first treated isolated mouse mesangial cells with increasing concentrations of dexamethasone (10-300 nM) for $24 \mathrm{~h}$ and measured the $\mathrm{S}_{1} \mathrm{P}_{1}$ mRNA expression levels compared to the vehicle-treated controls. As illustrated in Figure 2A, S1P mRNA expression was significantly downregulated upon stimulation with 10-300 nm dexamethasone. In addition, we treated male C57BL/6 mice with $10 \mathrm{mg} / \mathrm{kg}$ body weight dexamethasone (intraperitoneal injection) for $24 \mathrm{~h}$ and analyzed the mRNA expression of $\mathrm{S}_{1} \mathrm{P}_{1}$ in subsequently isolated kidney glomeruli. As seen in Figure 2B, S1P 1 mRNA expression was significantly reduced in dexamethasonetreated mice compared to the vehicle-treated control group.

\section{Downregulation of S1P 1 by dexametha- sone inhibits S1P-induced mesangial cell migration}

In principle, activation of distinct $\mathrm{S} 1 \mathrm{P}$ receptor subtypes by S1P is well known to induce cell migration of various cell types (for review, see Sanchez and Hla, 2004). In renal mesangial cells, we could previously demonstrate that inhibition of COX-2, which is up-regulated by $\mathrm{S}_{2} \mathrm{P}_{2}$, blocked S1P-induced migration (Völzke et al., 2014). In addition, the inhibitor of $\mathrm{S}_{1} \mathrm{P}_{1}$ and $\mathrm{S}_{3} \mathrm{P}_{3}$, VPC-23019, also diminished S1P-induced cell migration (Völzke et al., 2014), overall indicating that all three $\mathrm{S} 1 \mathrm{P}$ receptor subtypes, $\mathrm{S}_{1-3}$, play a crucial role for S1P-induced mesangial cell migration. Here, we further evaluated the pro-migratory effect of $\mathrm{S}_{1} \mathrm{P}_{1}$ and investigated whether downregulation of this receptor subtype by dexamethasone influences S1P-induced renal mesangial cell migration. As illustrated in Figure 3A, treatment with $1 \mu \mathrm{M}$ S1P clearly induced migration, which was significantly reduced in the presence of the $\mathrm{S}_{1} \mathrm{P}_{1}$ antagonist W146 (Sanna et al., 2006). Moreover, $4 \mathrm{~h}$ stimulation with the S1P agonist SEW2871 (Sanna et al., 2004) induced mesangial cells migration in a concentration dependent manner (Figure 3B). To further evaluate the pro-migratory role of $\mathrm{S}_{1} \mathrm{P}_{1}$ independent of $\mathrm{S}_{2} \mathrm{P}_{2}$ - and COX-2-mediated effects, we stimulated cells with p-FTY720, which binds to all S1P receptors, except ${\mathrm{S} 1 \mathrm{P}_{2}}_{2}$ (Brinkmann et al., 2002) and does not induce COX-2 protein expression in mesangial cells (Völzke et al., 2014). As shown in Figure 4, treatment with $1 \mu \mathrm{M}$ p-FTY720 for $4 \mathrm{~h}$ induced mesangial cell migration. This effect was significantly reduced after pretreatment with either $1 \mu \mathrm{M}$ W146 (Figure 4A) or $10 \mu \mathrm{M}$ VPC-32019 (an antagonist at $\mathrm{S1P}_{1 / 3}$ (Davis et al., 2005); Figure 4B). In contrast, pretreatment with the COX-2 inhibitor SC-236 did not affect p-FTY720-dependent induction of mesangial cells migration (Figure 4C). Overall, these data strongly suggest that the induction of mesangial cell migration by pFTY-720 is mediated by activation of $\mathrm{S}_{1} \mathrm{P}_{1}$, which further demonstrate the pro-migratory role of this receptor subtype in renal mesangial cells.
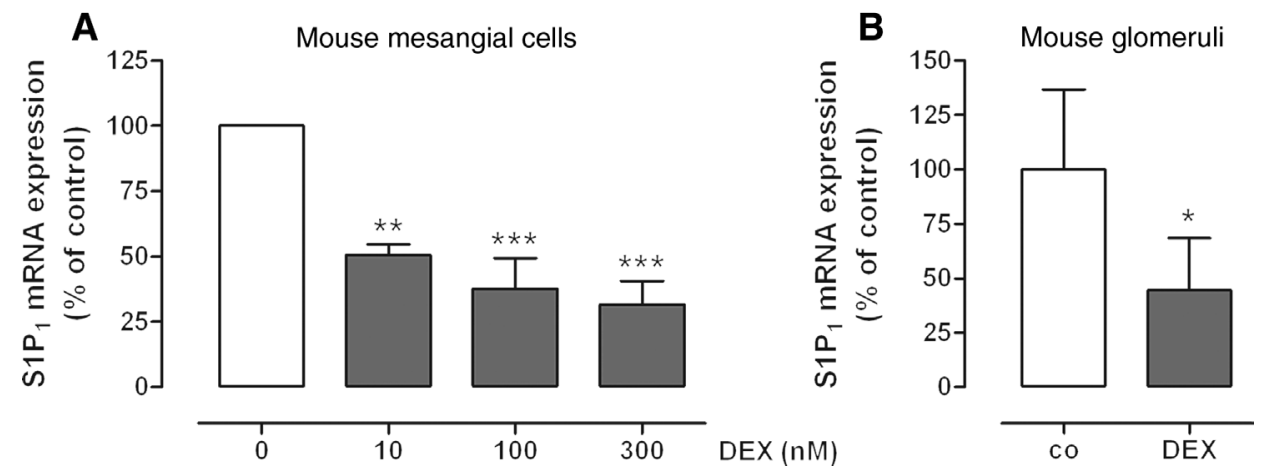

Figure 2: Dexamethasone downregulates $\mathrm{S}_{1} \mathrm{P}_{1}$ expression in mouse mesangial cells and isolated mouse glomeruli.

(A) $\mathrm{S}_{1} \mathrm{P}_{1} \mathrm{mRNA}$ expression levels after $24 \mathrm{~h}$ treatment with the indicated concentrations of dexamethasone (DEX). (B) S1P $\mathrm{P}_{1}$ RNA expression levels after intraperitoneally injection of $10 \mathrm{mg} / \mathrm{kg}$ body weight dexamethasone (DEX) in mice. After $24 \mathrm{~h}$, kidneys were harvested and taken for isolation of glomeruli by using a differential sieving method. All S1P ${ }_{1}$ RNA expression levels (gray bars) were determined by TaqMan ${ }^{\circledR}$ analysis and are shown relative to control cells (vehicle alone, white bars). (A) Results are expressed as mean \pm SEM ( $n=4$ ). (B) Results are expressed as mean \pm S.D. $(n=5) .{ }^{\star} p<0.05,{ }^{\star \star} p<0.01,{ }^{\star \star \star} p<0.001$, compared to the respective controls. 

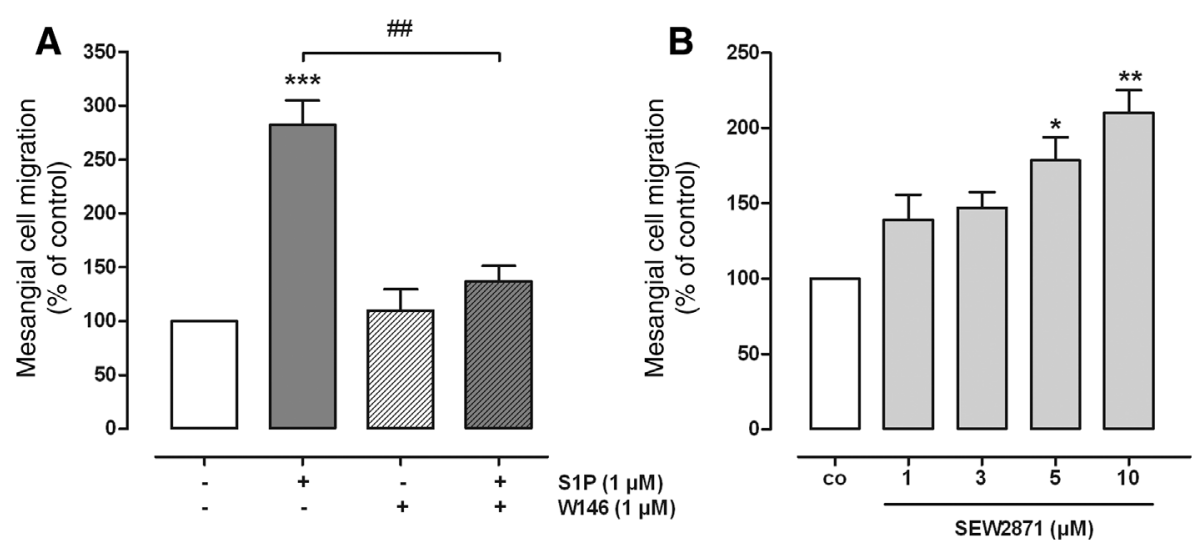

Figure 3: $\mathrm{S} 1 \mathrm{P}_{1}$ plays a crucial role for $\mathrm{S} 1 \mathrm{P}$-induced rat mesangial cell migration.

(A) Migration after $1 \mathrm{~h}$ pretreatment with $1 \mu \mathrm{M}$ W146 and additional $4 \mathrm{~h}$ of treatment with $1 \mu \mathrm{M} \mathrm{S1P.} \mathrm{(B)} \mathrm{Migration} \mathrm{after} 4 \mathrm{~h}$ of treatment with the indicated concentrations of SEW2871. Mesangial cell migration was measured by Boyden chamber assays. Results are shown relative to control cells (vehicle alone, white bars). All values are mean $\pm \operatorname{SEM}(n=3-4) .{ }^{\star} p<0.05,{ }^{\star \star} p<0.01,{ }^{\star \star \star} p<0.001$, compared to the respective controls. ${ }^{\# \#} p<0.01$, compared to the S1P-treated cells.
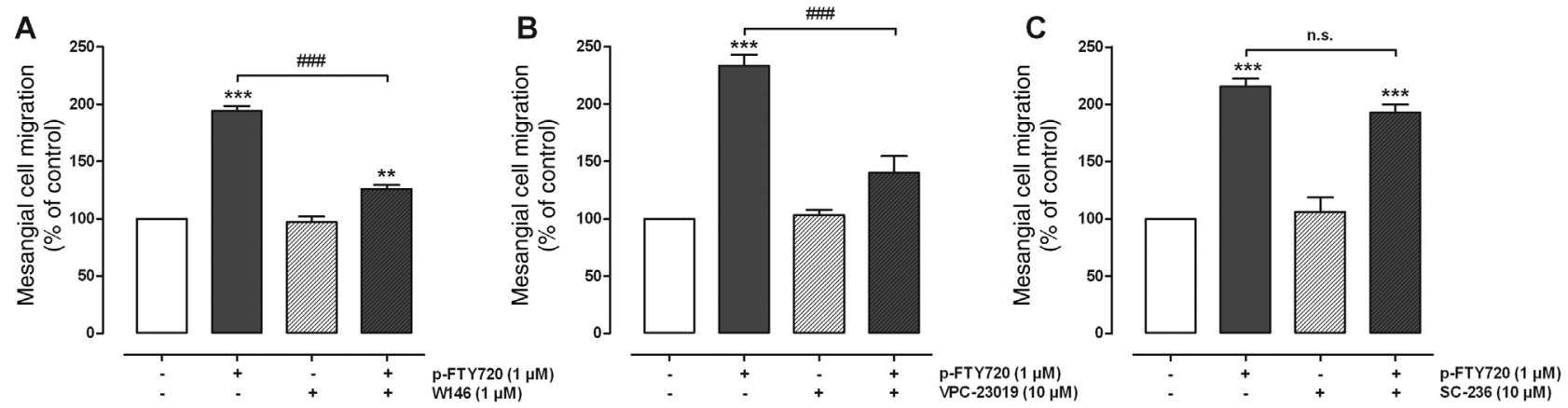

Figure 4: $\mathrm{S} 1 \mathrm{P}_{1}$ plays a crucial role for $\mathrm{p}$-FTY720-induced rat mesangial cell migration.

(A-C) Migration after $1 \mathrm{~h}$ pretreatment with either (A) $1 \mu \mathrm{M}$ W146, (B) $10 \mu \mathrm{M}$ VPC-23019, or (C) $10 \mu \mathrm{M} \mathrm{SC-236,} \mathrm{and} \mathrm{additional} 4 \mathrm{~h}$ treatment with $1 \mu \mathrm{M}$ p-FTY720. Mesangial cell migration was measured by Boyden chamber assays. Results are shown relative to control cells (vehicle alone, white bars). All values are mean \pm SEM $(n=3-4)$. ${ }^{\star *} p<0.01,{ }^{* \star *} p<0.001$, compared to the respective controls. ${ }^{\# \#} p<0.001$, compared to the S1P-treated cells (n.s.=not significant).

Next, we evaluated whether downregulation of $\mathrm{S}_{1} \mathrm{P}_{1}$ by dexamethasone alters S1P and p-FTY720 dependent induction of mesangial cell migration. As illustrated in Figure 5A, parallel treatment for $4 \mathrm{~h}$ with $100 \mathrm{~nm}$ dexamethasone significantly inhibited S1P-induced mesangial cell migration. Moreover, migration induced by $24 \mathrm{~h}$ treatment with $1 \mu \mathrm{M}$ S1P was completely abolished in the presence of $100 \mathrm{~nm}$ dexamethasone (Figure 5B). In addition, parallel stimulation for $4 \mathrm{~h}$ with $100 \mathrm{~nm}$ dexamethasone inhibited p-FTY720-induced migration (Figure 5C), whereas stimulation with $1 \mu \mathrm{M}$ p-FTY720 for $24 \mathrm{~h}$ did not induce mesangial cell migration at all (Figure 5D). In contrast, we detected no significant effect on mesangial cell migration after incubation with $100 \mathrm{~nm}$ dexamethasone alone for either $4 \mathrm{~h}$ [control (vehicle alone) $=100 \pm 0$,
DEX $(100 \mathrm{nM})=83.4 \pm 7.30 ;$ mean \pm SEM; $\mathrm{n}=3$ ] or $24 \mathrm{~h}$ [control (vehicle alone) $=100 \pm 0$, DEX $(100 \mathrm{nM})=84.5 \pm 5.30$; mean \pm SEM; $n=4]$. Most notably, the inhibitory effect of dexamethasone on S1P-induced migration was significantly reversed in the presence of the GR inhibitor RU-486 (Figure 5A, B).

\section{Discussion}

Glucocorticoids are commonly used to treat inflammatory renal diseases and their beneficial properties have been evaluated in various experimental settings (Kumar et al., 2009; Moysiadis et al., 2012). Our results provide strong 
A
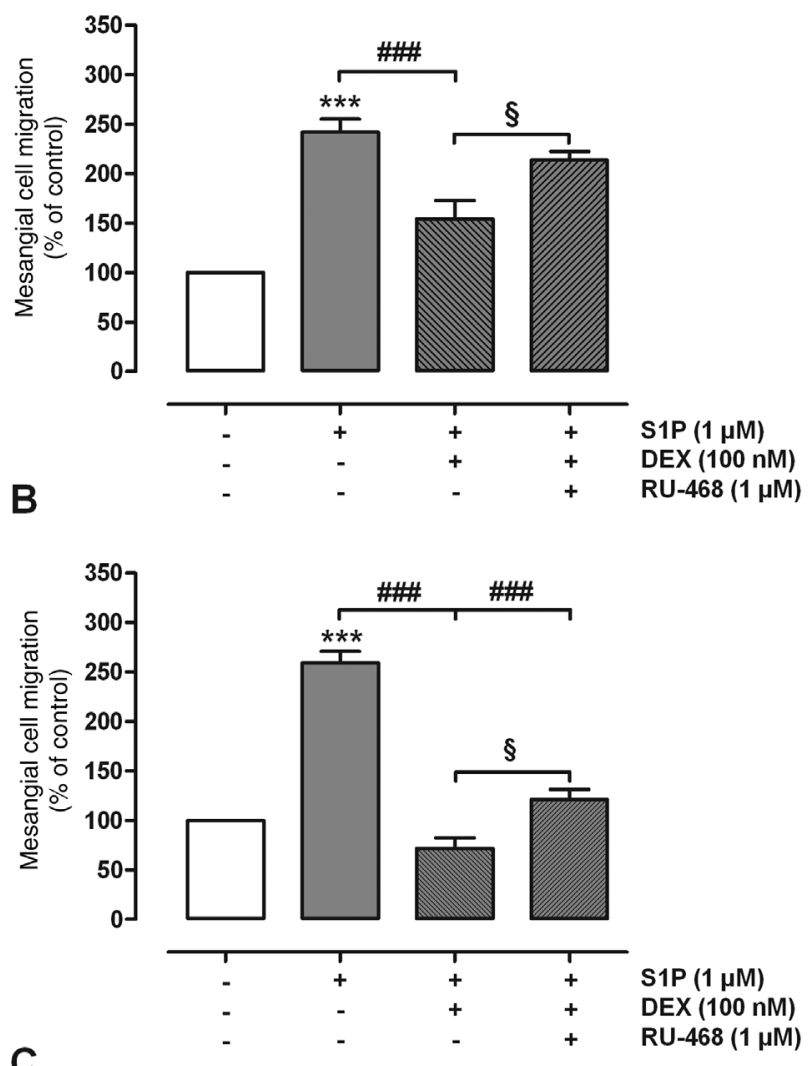

C

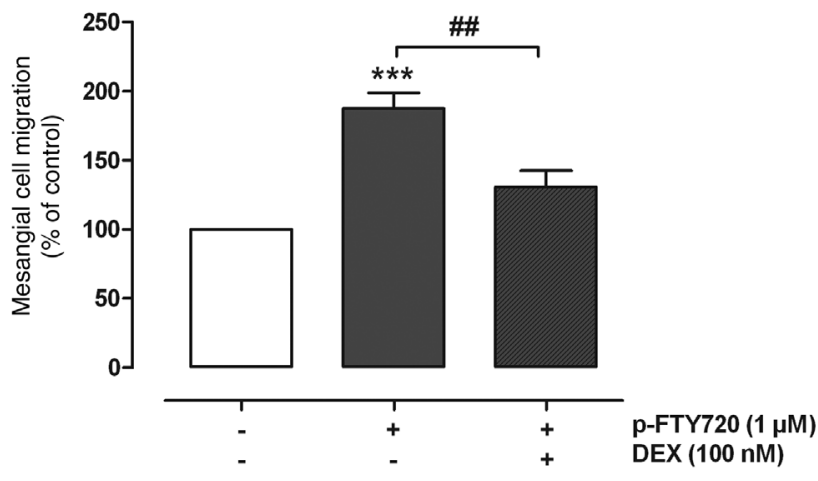

Figure 5: Dexamethasone downregulates S1P-induced rat mesangial cell migration.

$(\mathrm{A}, \mathrm{B})$ Migration after $4 \mathrm{~h}(\mathrm{~A})$ and $24 \mathrm{~h}(\mathrm{~B})$ treatment with $1 \mu \mathrm{M} \mathrm{S1P}$ in parallel with $100 \mathrm{~nm}$ dexamethasone (DEX) and $1 \mu \mathrm{M}$ RU-486.

(C) Migration after $4 \mathrm{~h}$ of treatment with $1 \mu \mathrm{M} \mathrm{p}-\mathrm{FTY7} 20$ and $100 \mathrm{~nm}$ dexamethasone (DEX). Mesangial cell migration was measured by Boyden chamber assays. Results are shown relative to control cells (vehicle alone, white bars). All values are mean \pm SEM $(n=3-4)$. ${ }^{\star \star \star} p<0.001$, compared to the respective controls. ${ }^{\# \#} p<0.05$,

\#\#\# $p<0.001$, compared to the S1P-treated cells. ${ }^{s} p<0.05$, compared to the S1P/DEX-treated cells.

evidence that part of the renal protective actions of glu-

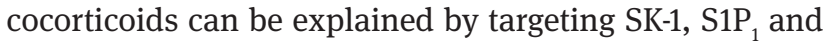
S1P receptor metabolism in resident glomerular cells.
Förster et al. (2010) demonstrated that dexamethasone alters sphingolipid metabolism by upregulation of neutral ceramidase and SK-1 expression and activity and by this protects mesangial cells from stress-induced apoptosis via enhanced formation of intracellular S1P. In addition, we demonstrate here for the first time that dexamethasone markedly reduced the expression of $\mathrm{S}_{1} \mathrm{P}_{1}$ in isolated mesangial cells and mouse glomeruli, which lead to lower S1P-induced mesangial cell migration. In this regard, it is still not clear when in the course of renal diseases mesangial cell migration occurs in vivo and how this contributes to the disease conditions. It is tempting to speculate that enhanced migration of mesangial cells could be beneficial, e.g., by counteracting initial mesangial cell lysis during forms of mesangioproliferative glomerulonephritis and contribute to resolution of disease. Definitely, further studies are required to address the role of mesangial cell migration in vivo in more detail.

The molecular mechanisms by which dexamethasone alters $\mathrm{S}_{1} \mathrm{P}_{1}$ expression levels are not known so far. Typically, glucocorticoids act via activation of GR, which is expressed in renal mesangial cells (Förster et al., 2010) and subsequent binding and activation of specific response elements, so-called GREs, in the promoter of target genes. Förster et al. (2010) demonstrated that upregulation of neutral ceramidase by dexamethasone is directly regulated via functional GREs. However, downregulation of gene expression by dexamethasone treatment, as we demonstrated here for $\mathrm{S} 1 \mathrm{P}_{1}$, could be the result of either direct binding to putative negative GREs or by transrepression involving the interaction between GR and a range of transcription factors like activator protein-1 or nuclear factor- $\mathrm{\kappa B}$ (for review, see De Bosscher et al., 2003). Whether one of these mechanisms is responsible for the reported downregulation of $\mathrm{S}_{1} \mathrm{P}_{1}$ expression upon dexamethasone treatment needs to be investigated in future studies.

In this regard, it is tempting to speculate whether dexamethasone-dependent SK-1 upregulation may have an impact on $\mathrm{S}_{1} \mathrm{P}_{1}$ expression. Data by Meyer zu Heringdorf et al. (2001) showed that activation of S1P receptors enhance SK-1 activity in human embryonic kidney cells (HEK293). Most interestingly, these authors speculated that HEK293 cells may respond to SK-1 upregulation and activation by either an up- or downregulation of distinct S1P receptor subtypes. Whether this could explain the reduced $\mathrm{S}_{1} \mathrm{P}_{1}$ expression upon dexamethasone stimulation in renal mesangial cells is not yet proven. However, we previously reported that both, glitazones (rosiglitazone and troglitazone) and dexamethasone indeed enhance the expression and activity of SK-1 (Förster et al., 2010; Koch et al., 2012), but still have opposite effects on $\mathrm{S}_{1} \mathrm{P}_{1}$ 
mRNA and protein expression (Figure 1; Koch et al., 2013b) indicating that SK-1 activation does not directly influence $\mathrm{S}_{1} \mathrm{P}_{1}$ expression in renal mesangial cells. Interestingly, $\mathrm{S}_{1} \mathrm{P}_{3}$ mRNA expression was significantly decreased upon dexamethasone treatment, whereas the protein expression was not altered (Table 1 and Figure 1E). Obviously, in rat mesangial cells $\mathrm{S}_{3} \mathrm{P}_{3}$ expression seems to be regulated not only on the transcriptional level, but also on a posttranscriptional level by altering mRNA stability and/ or translational effects, which should be investigated in further studies.

Functionally, we clearly show that $\mathrm{S}_{1} \mathrm{P}_{1}$ plays an essential role mediating the S1P-induced migration of renal mesangial cells and that dexamethasone inhibits the migratory response by downregulation of this receptor subtype. In principle, $\mathrm{S}_{1} \mathrm{P}_{1}$ and $\mathrm{S}_{1} \mathrm{P}_{3}$ are well known to trigger migration of various cell types (for review, see Sanchez and Hla, 2004). In renal mesangial cells we additionally demonstrated that activation of COX-2 and enhanced formation of $\mathrm{PGE}_{2}$ via $\mathrm{S}_{1} \mathrm{P}_{2}$ triggers S1P-induced cell migration (Völzke et al., 2014). In parallel, our own data using several agonists and antagonists for $\mathrm{S}_{1} \mathrm{P}_{1}$ show that this receptor subtype also plays a crucial role for S1Pinduced mesangial cell migration. First of all, the dual ${\mathrm{S} 1 \mathrm{P}_{1 / 3}}$ antagonist VPC-23019 (Davis et al., 2005) diminished S1P- and pFTY720-induced mesangial cell migration (Völzke et al., 2014, Figure 4B). Further, SEW2871 significantly enhanced mesangial cell migration. As shown in Figure 3B, we detected enhanced migration of rat mesangial cells after stimulation with concentration above $1 \mu \mathrm{M}$ with significant effects at 5 and $10 \mu \mathrm{M}$ SEW2871. Sanna et al. (2004) established SEW2871 as a selective $\mathrm{S}_{1} \mathrm{P}_{1}$ agonist with no effect on $\mathrm{S}_{1} \mathrm{P}_{2-5}$ at concentrations up to $10 \mu \mathrm{M}$. Therefore and also considering that VPC-23019 inhibited S1P- as well as p-FTY720-induced migration, we think that the pro-migratory effect of SEW2871 is due to $\mathrm{S}_{1} \mathrm{P}_{1}$ activation. However, we cannot fully exclude, that the effect of 5 and $10 \mu \mathrm{M}$ SEW2871 on mesangial cell migration could be mediated via activation of other receptors independently of S1P receptors. In this regard, it is tempting to speculate that also high concentrations of W146 may act quite unspecific. This might explain the fact that W146 blocked S1P-induced migration almost completely (Figure 3A), which in a way contrasts to our previous findings about the role of $\mathrm{S}_{1} \mathrm{P}_{2}$-mediated COX-2 activation and subsequently induced mesangial cell migration (Völzke et al., 2014). Overall, we suggest that both, COX-2-dependent $\left(\right.$ via $\left.\mathrm{S}_{2} \mathrm{P}_{2}\right)$ and independent (via S1P $\mathrm{P}_{1}$ ) mechanisms are involved in the migratory response of renal mesangial cells upon S1P treatment. This hypothesis should be verified by genetic approaches in future studies.
To investigate effects without affecting $\mathrm{S}_{2} \mathrm{P}_{2}$ we used p-FTY720, which is known to activate all S1P receptors except $\mathrm{S}_{2} \mathrm{P}_{2}$ (Brinkmann et al., 2002) and does not induce COX-2 expression (Völzke et al., 2014). Interestingly, stimulation with p-FTY720 for $4 \mathrm{~h}$ clearly induced mesangial cell migration. This effect is blocked by pretreatment with W146 and VPC-23019 (Figure 4A and B), which further underlines the role of $\mathrm{S}_{1} \mathrm{P}_{1}$ for mesangial cell migration. In principle, FTY720 (fingolimod) and its phosphorylated form are known to act as 'functional antagonists' at S1P (for review, see Brinkmann et al., 2010). After initial receptor activation, which is responsible for the induction of mesangial cell migration upon short time stimulation with p-FTY720, fingolimod causes $\mathrm{S}_{1} \mathrm{P}_{1}$ to internalize from cell membranes resulting in receptor degradation and inhibition of cell migration. In this context, the current data raise the interesting question of whether dexamethasone mimics the effect of fingolimod on lymphocyte trafficking via transcriptional downregulation of pro-migratory $\mathrm{S}_{1} \mathrm{P}_{1}$, and if so, whether this effect contributes to the known anti-inflammatory properties of glucocorticoids. Beside the well established role of S1P receptors for the mediation of migratory cell responses, our previous findings suggested that also SK-1 activation is crucial for the migration of cells (Döll et al., 2007; Klawitter et al., 2007). Döll et al. (2007) showed that SK-1 is critically involved in the migration of the breast adenocarcinoma cell line MCF7 stimulated by prolactine. In renal mesangial cells it was shown that downregulation of SK-1 by siRNA transfection abrogated the migratory response induced by S1P (Klawitter et al., 2007), suggesting that SK-1 is obviously required for S1P-induced migration. Thus, upregulation of SK-1 activity and intracellular formation of S1P by dexamethasone as it was shown by Förster et al. (2010) is supposed to lead to higher mesangial cell migration. Our present data now demonstrate that dexamethasone inhibits S1P-induced migration via reduced expression of $\mathrm{S}_{1} \mathrm{P}_{1}$. Obviously, the downregulation of $\mathrm{S}_{1} \mathrm{P}_{1}$ overrides the fostering role of SK-1 on S1P-induced mesangial cell migration upon exposure to dexamethasone. Moreover, it is tempting to speculate that dexamethasone also affects putative S1P transporters and thereby alters the intra- and extracellular S1P concentrations and the activation status of the participating S1P receptors. In this regard, Nieuwenhuis et al. (2009) demonstrated that dexamethasone upregulates Abcc1 expression in human fibroblasts, which is one of the putative S1P transporters believed to be involved in shuttling S1P across membranes (Mitra et al., 2006). In contrast to our findings, these authors did not see any changes in $\mathrm{S}_{1} \mathrm{P}_{1}$ expression (Nieuwenhuis et al., 2009). Whether dexamethasone alters the expression and activity of putative 
S1P transporters, such as Abcc1 or spinster-2, in renal mesangial cells and if this in turn complements the crosstalk between the migratory response of SK-1 activation and S1P formation and reduced expression of pro-migratory $\mathrm{S} 1 \mathrm{P}_{1}$ after dexamethasone stimulation needs to be clarified in future studies.

Taken together, we demonstrate that dexamethasone inhibits S1P-induced mesangial cell migration via downregulation of pro-migratory $\mathrm{S}_{1} \mathrm{P}_{1}$. Obviously, dexamethasone has a variety of functional important effects on SK-1 and $\mathrm{S}_{1} \mathrm{P}_{1}$ signaling pathways, in renal mesangial cells, which probably form part of the known renal protective effects of glucocorticoids.

\section{Materials and methods}

\section{Chemicals}

Dexamethasone, betamethasone, hydrocortisone, aldosterone and RU-486 were from Sigma-Aldrich (Steinheim, Germany). S1P, phospho-FTY720 (p-FTY720), and SEW2871 were obtained from Cayman Chemicals (Ann Arbor, MI, USA). VPC-23019 and W146 were from Avanti Polar Lipids Inc. (Alabaster, AL, USA). SC-236 was obtained from Merck (Darmstadt, Germany).

\section{Cell culture and stimulation}

Rat and mouse glomerular mesangial cells were isolated, cultivated and characterized as previously described (Pfeilschifter and Vosbeck, 1991; Hofmann et al., 2008). For experiments in this study, rat mesangial cells between passages 13-18 and mouse mesangial cells between passages 8-12 were seeded in 60-mm-diameter dishes and used after reaching confluence. Prior stimulation, rat mesangial cells were preincubated with Dulbecco's modified Eagle medium (DMEM) containing $0.1 \mathrm{mg} / \mathrm{ml}$ of fatty acid-free bovine serum albumin. Mouse mesangial cells were pre-incubated with DMEM containing $0.1 \mathrm{mg} / \mathrm{ml}$ of fatty acid-free bovine and $1 \%$ fetal bovine serum (Merck, Darmstadt, Germany). After $24 \mathrm{~h}$, mesangial cells were stimulated with the indicated substances. Control cells were treated with vehicle alone. Final solvent concentration did not exceed $0.2 \%(\mathrm{v} / \mathrm{v})$.

\section{Two-step polymerase chain reaction (PCR) analysis}

Two-step PCR analysis was performed as described (Koch et al., 2012). Briefly, $1.2 \mu \mathrm{g}$ of total RNA was isolated with TRIZOL ${ }^{\mathrm{TM}}$ reagent (Sigma-Aldrich, Steinheim, Germany) according to the manufacturer's protocol and used for reverse transcriptase polymerase chain reaction (RT-PCR; RevertAid ${ }^{\mathrm{TM}}$ first strand cDNA synthesis kit, Thermo Fisher Scientific, Waltham, MA, USA) utilizing an oligo (dT) primer for amplification. Real-time PCR (TaqMan ${ }^{\circledR}$ ) was performed using the Applied Biosystems 7500 Fast Real-Time
PCR System. The TaqMan system, all probes, primers, the reporter dyes 6-FAM and VIC, and the software were from Life Technologies (Darmstadt, Germany). The following TaqMan ${ }^{\circledast}$ assays were used: rat S1P, Rn00568869_m1; rat S1P, Rn00567877_m1; rat S1P, Rn02758880_s1; rat S1P_Rn01408085_s1; rat S1P 5 , Rn01486962_g1; mouse S1P 1 , Mm00514644_m1. The cycling conditions were as follows: $95^{\circ} \mathrm{C}$ for $15 \mathrm{~min}$ ( 1 cycle), $95^{\circ} \mathrm{C}$ for $15 \mathrm{~s}$ and $60^{\circ} \mathrm{C}$ for $1 \mathrm{~min}(40$ cycles). The threshold cycle $\left(\mathrm{C}_{\mathrm{t}}\right)$ was calculated by the instrument's software (7500 Fast System SDS Software version 1.4). Analysis of the relative mRNA expression was performed using the $\Delta \Delta C_{t}$ method. Eukaryotic $18 \mathrm{~S}$ ribosomal RNA (Life Technologies, Darmstadt, Germany) was used for normalization.

\section{Western blot analysis}

Following stimulation the medium was removed and the cells were washed once with phosphate-buffered saline (PBS) solution. Thereafter, cells were scraped into ice-cold lysis buffer (50 mM Tris-HCl, pH 7.4, $150 \mathrm{~mm} \mathrm{NaCl}, 10 \%$ glycerol, 1\% Triton X-100, 2 mm ethylenediaminetetraacetic acid (EDTA), $2 \mathrm{~mm}$ ethylene glycol-bis( $\beta$-aminoethyl ether)$\mathrm{N}, \mathrm{N}, \mathrm{N}^{\prime}, \mathrm{N}^{\prime}$,-tetraacetic acid (EGTA), $40 \mathrm{~mm} \beta$-glycerophosphate, $50 \mathrm{~mm}$ sodiumfluoride, $10 \mu \mathrm{g} / \mathrm{ml}$ leupeptin, $10 \mu \mathrm{g} / \mathrm{ml}$ pepstatin $\mathrm{A}, 1 \mathrm{~mm}$ phenylmethyl sulfonyl fluoride) and homogenized by sonication. The samples were then centrifuged for $10 \mathrm{~min}$ at $16,200 \mathrm{~g}$ and the supernatant was taken for protein determination. Cell lysates containing equal amounts of protein $(50 \mu \mathrm{g})$ were separated on sodium dodecyl sulfate-polyacrylamide gel electrophoresis (10\% acrylamide gel) and transferred to a nitrocellulose membrane and subjected to Western blot analysis as described previously (Huwiler et al., 1995). The S1P antibody was from ProSci Inc. (Poway, USA). The S1P ${ }_{1}$ antibody specificity was confirmed using a corresponding blocking peptide (ProSci Inc., Poway, USA) exactly as described (Koch et al., 2013b). The $\mathrm{S}_{3} \mathrm{P}_{3}$ antibody was obtained from Cayman Chemicals (Ann Arbor, MI, USA). The $\beta$-actin antibody was purchased from Santa Cruz (Heidelberg, Germany). S1P ${ }_{1}$ and ${\mathrm{S} 1 \mathrm{P}_{3}}_{3}$ antibodies were used at dilutions of 1:1000 and the $\beta$-actin antibody was used at a dilution of 1:3000.

\section{Cell migration assay}

Rat mesangial cell migration was measured using a Boyden chamber assay exactly as described (Klawitter et al., 2007). Shortly, mesangial cell migration was measured as the ability of cells to migrate through a Transwell filter (6.5 mm diameter, $8 \mathrm{~mm}$ pore size). After serum starvation, cells were detached by trypsinization and seeded into Transwell filters at $1 \times 10^{5}$ cells in $100 \mathrm{ml}$ starvation medium with or without the indicated stimuli; $500 \mathrm{ml}$ of starvation medium were placed in the lower compartment, and the cells were left to migrate for the indicated time periods. After treatment, the medium was removed and the non-migrating cells were removed from the filter by wiping the filter with a cotton pad. The filters were washed twice with PBS, fixed in 4\% formaldehyde in PBS for 30 min at room temperature and again washed in water and methanol. Thereafter, the cells were stained with 40,6-diamidino-2-phenylindole (DAPI; $1 \mathrm{mg} / \mathrm{ml}$ ) for $15 \mathrm{~min}$ at $37^{\circ} \mathrm{C}$, washed with methanol and dried. Cells that had migrated into the pores of the filters were counted using fluorescence microscopy. 


\section{Animal experiments}

All animal experiments were conducted in accordance with the German Animal Protection Law and were approved by the Ethics Review Committee of the District Governments of Darmstadt, Germany. Animal experiments were performed exactly as described (Förster et al., 2010). Briefly, male C57BL/6 mice, 8 weeks old, were intraperitoneal injected with dexamethasone (10 $\mathrm{mg} / \mathrm{kg}$ body weight) dissolved in PBS. Control animals were injected with $150 \mathrm{ml}$ of PBS. After $24 \mathrm{~h}$, kidneys ( $n=5$ per group) were harvested and taken for isolation of glomeruli by using a differential sieving method.

\section{Statistical analysis}

All data were statistically analyzed by one-way analysis of variance followed by Bonferroni's post hoc test for multiple comparisons or by Student's $t$-test for unpaired analysis (GraphPad Prism version 5; GraphPad Software, San Diego, CA, USA). Differences with $p<0.05$ were considered to be significant.

Acknowledgments: We gratefully acknowledge Juliane Dreke, Daniel Staudenraus, and Anna-Maria Grau (all pharmazentrum frankfurt/ZAFES) for excellent technical assistance. This work was supported by the German Research Foundation (KO3940/1-1, PF361/7-2, SFB1039, SPP1267/2), the Alfons und Gertrud Kassel-Stiftung (to A.K.), and the Swiss National Science Foundation (310030, 135619).

\section{References}

Brinkmann, V., Davies, M.D., Heise, C.E., Albert, R., Cottens, S., Hof, R., Bruns, C., Prieschl, E., Baumruker, T., Hiestand, P., et al. (2002). The immune modulator FTY720 targets sphingosine 1-phosphate receptors. J. Biol. Chem. 277, 21453-21457.

Brinkmann, V., Billich, A., Baumruker, T., Heining, P., Schmouder, R., Francis, G., Aradhye, S., and Burtin, P. (2010). Fingolimod (FTY720): discovery and development of an oral drug to treat multiple sclerosis. Nat. Rev. Drug Discov. 9, 883-897.

Davis, M.D., Clemens, J.J., Macdonald, T.L., and Lynch, K.R. (2005). Sphingosine 1-phosphate analogs as receptor antagonists. J. Biol. Chem. 280, 9833-9841.

De Bosscher, K., Vanden Berghe, W., and Haegeman, G. (2003). The interplay between the glucocorticoid receptor and nuclear factor $-\kappa B$ or activator protein-1: molecular mechanisms for gene repression. Endocr. Rev. 24, 488-522.

Döll, F., Pfeilschifter, J., and Huwiler, A. (2007). Prolactin upregulates sphingosine kinase-1 expression and activity in the human breast cancer cell line MCF7 and triggers enhanced proliferation and migration. Endocr. Relat. Cancer 14, 325-335.

Förster, A., Emmler, T., Schwalm, S., Ebadi, M., Heringdorf, D.M., Nieuwenhuis, B., Kleuser, B., Huwiler, A., and Pfeilschifter, J. (2010). Glucocorticoids protect renal mesangial cells from apoptosis by increasing cellular sphingosine-1-phosphate. Kidney Int. 77, 870-879.

Hofmann, L.P., Ren, S., Schwalm, S., Pfeilschifter, J., and Huwiler, A. (2008). Sphingosine kinase 1 and 2 regulate the capacity of mesangial cells to resist apoptotic stimuli in an opposing manner. Biol. Chem. 389, 1399-1407.

Huwiler, A., Stabel, S., Fabbro, D., and Pfeilschifter, J. (1995). Platelet-derived growth factor and angiotensin II stimulate the mitogen-activated protein kinase cascade in renal mesangial cells comparison of hypertrophic and hyperplastic agonists. Biochem. J. 305, 777-784.

Jung-Testas, I. and Baulieu, E.E. (1983). Inhibition of glucocorticosteroid action in cultured L-929 mouse fibroblasts by RU 486, a new antiglucocorticosteroid of high affinity for the glucocorticosteroid receptor. Exp. Cell Res. 147, 177-182.

Katsuma, S., Hada, Y., Ueda, T., Shiojima, S., Hirasawa, A., Tanoue, A., Takagaki, K., Ohgi, T., Yano, J., and Tsujimoto, G. (2002). Signalling mechanisms in sphingosine 1-phosphate-promoted mesangial cell proliferation. Genes Cells 7, 1217-1230.

Klawitter, S., Hofmann, L.P., Pfeilschifter, J., and Huwiler, A. (2007). Extracellular nucleotides induce migration of renal mesangial cells by upregulating sphingosine kinase-1 expression and activity. Br. J. Pharmacol. 150, 271-280.

Koch, A., Völzke, A., Wünsche, C., Meyer zu Heringdorf, D., Huwiler, A., and Pfeilschifter, J. (2012). Thiazolidinedione-dependent activation of sphingosine kinase 1 causes an anti-fibrotic effect in renal mesangial cells. Br. J. Pharmacol. 166, 1018-1032.

Koch, A., Pfeilschifter, J., and Huwiler, A. (2013a). Sphingosine 1-phosphate in renal diseases. Cell. Physiol. Biochem. 31, 745-760.

Koch, A., Völzke, A., Puff, B., Blankenbach, K., Meyer zu Heringdorf, D., Huwiler, A., and Pfeilschifter, J. (2013b). PPAR $\gamma$ agonists upregulate sphingosine 1-phosphate (S1P) receptor 1 expression, which in turn reduces S1P-induced $\left[\mathrm{Ca}^{2+}\right]_{i}$ increases in renal mesangial cell. Biochim. Biophys. Acta 1831, 1634-1643.

Kumar, S., Allen, D.A., Kieswich, J.E., Patel, N.S., Harwood, S., Mazzon, E., Cuzzocrea, S., Raftery, M.J., Thiemermann, C., and Yaqoob, M.M. (2009). Dexamethasone ameliorates renal ischemia-reperfusion injury. J. Am. Soc. Nephrol. 20, 2412-2425.

Meyer zu Heringdorf, D., Lass, H., Kuchar, I., Lipinski, M., Alemany, R., Rümenapp U., and Jakobs, K.H. (2001). Stimulation of intracellular sphingosine-1-phosphate production by G-proteincoupled sphingosine-1-phosphate receptors. Eur. J. Pharmacol. 414, 145-154.

Mitra, P., Oskeritzian, C.A., Payne, S.G., Beaven, M.A., Milstien, S., and Spiegel, S. (2006). Role of ABCC1 in export of sphingosine1-phosphate from mast cells. Proc. Natl. Acad. Sci. USA 103, 16394-16399.

Moysiadis, D.K., Perysinaki, G.S., Bertsias, G., Stratakis, S., Kyriacou, K., Nakopoulou, L., Boumpas, D.T., and Daphnis. E. (2012). Early treatment with glucocorticoids or cyclophosphamide retains the slit diaphragm proteins nephrin and podocin in experimental lupus nephritis. Lupus 21, 1196-1207.

Nieuwenhuis, B., Lüth, A., Chun, J., Huwiler, A., Pfeilschifter, J., Schäfer-Korting, M., and Kleuser, B. (2009). Involvement of the $A B C$-transporter $A B C C 1$ and the sphingosine 1-phosphate receptor subtype S1P(3) in the cytoprotection of human fibroblasts by the glucocorticoid dexamethasone. J. Mol. Med. (Berl.) 87, 645-657.

Pfeilschifter, J. and Vosbeck, K. (1991). Transforming growth factor beta 2 inhibits interleukin 1 beta- and tumor necrosis factor 
$\alpha$-induction of nitric oxid synthase in rat renal mesangial cells. Biochem. Biophys. Res. Commun. 175, 372-379.

Sanchez, T. and Hla, T. (2004). Structural and functional characteristics of S1P receptors. J. Cell. Biochem. 92, 913-922.

Sanna, M.G., Liao, J., Jo, E., Alfonso, C., Ahn, M.Y., Peterson, M.S., Webb, B., Lefebvre, S., Chun, J., Gray, N., et al. (2004). Sphingosine 1-phosphate (S1P) receptor subtypes S1P1 and S1P3, respectively, regulate lymphocyte recirculation and heart rate. J. Biol. Chem. 279, 13839-13848.

Sanna, M.G., Wang, S.K., Gonzalez-Cabrera, P.J., Don, A., Marsolais, D., Matheu, M.P., Wei, S.H., Parker, I., Jo, E., Cheng, W.C., et al.
(2006). Enhancement of capillary leakage and restoration of lymphocyte egress by a chiral S1P1 antagonist in vivo. Nat. Chem. Biol. 2, 434-441.

Strub, G.M., Maceyka, M., Hait, N.C., Milstien, S., and Spiegel, S. (2010). Extracellular and intracellular actions of sphingosine1-phosphate. Adv. Exp. Med. Biol. 688, 141-155.

Völzke, A., Koch, A., Meyer Zu Heringdorf, D., Huwiler, A., and Pfeilschifter, J. (2014). Sphingosine 1-phosphate (S1P) induces COX-2 expression and $\mathrm{PGE}_{2}$ formation via S1P receptor 2 in renal mesangial cells. Biochim. Biophys. Acta 1841, 11-21. 